\title{
EL DIARIO COMO PRÁCTICA NARRATIVA Y VISUAL
}

Resumen: Este artículo tiene como objetivo principal realizar una aproximación tanto teórica como metodológica al diario, como práctica narrativa y visual, mediante la articulación entre la etnografia, las prácticas visuales y la cotidianidad. Desarrollaré este argumen-

to en una reflexión sobre dos trabajos que he ido realizando $Z$ en los últimos años: Siena'ga y Re/membranzas, por medio de los cuales he explorado formas de expresión entre la escritura y las prácticas visuales (fotografía y video), en las que las decisiones estéticas están ligadas a las reflexiones teóricas, etnográficas, y viceversa. Parto de las políticas y po-éticas de locación y de los conocimientos situados donde producimos conocimiento. Se trata de un pensar con y desde el cuerpo que nos permite generar sentido, es decir, tomar posición a partir de la vulnerabilidad y la intimidad donde se producen nuestras relaciones con los otros y con el mundo. Asimismo, este artículo es una manera de reflexionar sobre mi trabajo en la academia y mis producciones culturales implicadas en las políticas y po-éticas de la producción de conocimiento, y de imaginar e inventar formas novedosas de aproximación y traducción hacia esos excesos e indeterminaciones que nos están presentando los contextos en que trabajamos, vivimos, deseamos, amamos, etc.

Palabras clave: Diario, prácticas narrativas, prácticas visuales, etnografia, cotidianidad. 
Abstract: The main purpose of this article is to make an approach both theoretical and methodological to the journal as noraLive and visual practice, from the articulation of ethnograbe developed throughout a reflection on two works । have been making over the last years: Siena'ga and Re/membranzas. With them I have explored ways for (photography and video) where esthetic decisions are related to theoretical and ethnographic reflecttons. I start from the location's politics and po/ etics, from the situated knowledge where this is produced. Thinking with and from the body diving us to generate sense, that is, a position from with others and with the word were our relations article is a way for reflecting on my academic work and my cultural productions involved in the politics and po/etics of knowledge production, imagining and the excess and indeterminacy we receive from the envionments in which we work, live, wish, love and so on. Key Words: Journal, Narrative Practices, Visual Practices, Ethno-
graphy, Quotidian life. 


\section{PRÁCTICAS VISUALES, DIARIO, ETNOGRAFÍA, COTIDIANIDAD, CONOCIMIENTOS SITUADOS Y SENTIDOS DEL TIEMPO, EL ESPACIO Y LA MEMORIA}

Siena'ga y Re-membranzas ${ }^{2}$ son prácticas visuales guiadas por un ensamblaje intuitivo de imágenes y memorias, a través de capas temporales, reflexiones y texturas con que he tratado de evocar no solo lo que es visible, sino también la experiencia sensorial del movimiento y la memoria. Los dos proyectos, en sus temáticas particulares, son una yuxtaposición poética del tiempo, los lugares, la cultura material y la experiencia vivida. Desde acá, me interesa explorar las múltiples gramáticas de sentido del tiempo, el espacio y la memoria.

Mi propuesta del diario, como práctica narrativa y visual, parte de situarme en una aproximación a lo visual desde lo afectivo y la intimidad. Es decir, estoy aproximándome a los afectos desde la perspectiva de Kathleen Steward (2007), la cual indudablemente entra en conversación con las estructuras de sentir de R. Williams y parte de ver cómo los afectos ordinarios tienen la capacidad de afectar y afectarnos, lo cual da a la cotidianidad la calidad de movilidad continua de relaciones, contingencias y emergencias. Desde esta perspectiva es que sitúo la propuesta del diario, como práctica narrativa y visual, en la que la producción, recolección y ensamblaje de las imágenes está totalmente permeada por impulsos, intensidades, sensaciones, encuentros, compulsiones y sueños.

Un posicionamiento en la relación subjetiva entre objeto y sujeto, que me ha llevado a detenerme en los usos y significados privados de los recuerdos, las historias familiares, los en-

Siena'ga es la creación de un espacio-tiempo a través de memorias, deseos y fantasías personales y familiares. Por medio de una aproximación textual y visual, he ido creando Siena'ga a través de imágenes que cargan con sedimentos y residuos del pasado, presente y devenir. Este proyecto es un recorrido, cuyo fin es el de navegar e interconectar tres lugares que han sido, y son, parte de la experiencia histórica de mi familia: Ciénaga y Bogotá (Colombia) y Siena (Italia). Dicho detour es una forma de explorar y aproximarme a las historias inscritas en mi cuerpo en relación con los otros y con los mundos en los que he vivido, y que me han tocado, permeado y cambiado.

Este trabajo audiovisual y etnográfico se basa en un recorrido por diferentes escenarios de memorias de la violencia del Proceso de Comunidades Negras (PCN), la Comunidad de Paz de San José de Apartadó y la Organización de Mujeres Wayuu Munsurat. Partiendo de la articulación tiempo/imagen, me interesa analizar cómo las prácticas audiovisuales están abriendo espacios para reflexionar sobre otras temporalidades, sobre la memoria, entendida, en términos de Benjamin, como la ruina, que no significa la decadencia, el pasado, sino la interposición y coexistencia de tiempos. 
cuentros, la cotidianidad y las herramientas visuales que en ellas se manifiestan. El denominado objeto empírico no existe "ahí fuera", sino que lo crea el encuentro entre objeto y sujeto, mediado por el bagaje teorético que cada uno trae consigo en el encuentro. Esto transforma el análisis de una "aplicación" instrumentalista en una interacción performativa entre el objeto, la teoría y el sujeto.

Los dos proyectos que expongo acá los he desarrollado en el análisis sociocultural y los lenguajes estéticos. Me sitúo en una reflexión sobre la(s) epistemología(s) de lo visual y las posibilidades de producción de conocimiento originado en lo visual. Por medio de estos proyectos he explorado formas de expresión entre la escritura y las prácticas visuales (fotografía y video) en las que las decisiones estéticas han estado ligadas a las reflexiones teóricas y etnográficas, y viceversa. En este contexto, entiendo las prácticas visuales y etnográficas como formas de crítica cultural donde la teoría, la investigación y la creación coexisten y se elaboran conjuntamente, y al mismo tiempo me interesa la reflexión sobre la manera como estos trabajos están implicados en las políticas y po-éticas de lo visual.

Desde el momento en que comencé a trabajar a partir y sobre lo visual, mis formas de aproximación se complejizaron y enriquecieron, ya que no pretendo únicamente utilizar los medios visuales en la investigación para producir trabajos visuales, como videos, ensayos fotográficos, etc., sino que mis intereses giran alrededor de una reflexión sobre la visualidad en si misma, que permite una apuesta por otras formas de generar conocimiento y sentido, a la vez que una reflexión sobre lo que implica el mirar, el ser visto y el mostrar (Mitchell, 2003), es decir, sobre la forma como opera la visualidad en la cotidianidad. Tanto en la construcción social de lo visual como en la construcción visual de lo social, la visualidad requiere que nos centremos en las relaciones entre lo visto y el que ve. De esta manera, en los procesos de realización de los proyectos que he nombrado anteriormente han operado también estos cuestionamientos.

\section{Siena'ga}

Mis intereses de aproximación desde y hacia lo visual comenzaron con fines, no académicos ni de investigación ni de "producción de obra", sino principalmente por motivos personales, es decir, por la necesidad que senti de "documentar" ciertos eventos de mi vida. La primera vez que comencé a explorar con una videocámara fue cuando fui a Ciénaga, Magdalena, con mi abuela y mi tía, que no regresaban después de treinta años. Primero realicé un video tipo home-movie, para toda la familia, sobre este regreso y después, con una buena distancia de tiempo, realicé el video-ensayo de Siena'ga, 
guiada por mis intereses académicos de trabajar en investigación/creación, al igual que tratando de explorar formas de aproximación y traducción de esa experiencia utilizando el video y la fotografía. Así, el paso de una home-movie a una práctica artística-investigativa no es de un espacio determinado a otro, sino más bien una forma de trabajar en los intervalos entre lo personal y lo público, entre el adentro y el afuera, entre la intimidad y lo colectivo.

Siena'ga es el resultado de un proceso que comenzó con un acercamiento a un evento familiar, a manera de home-movie, solo para que el resto de mi familia, que no regresaba hacía mucho años, viera cómo estaba Cienaga después de tanto tiempo de haberla dejado, con algunos encuentros con la gente que aún habitaba alli, y al mismo tiempo, es una forma de acercarme a este evento a través de la fotografía y el video. Con el tiempo este proyecto se convirtió en una yuxtaposición de biografias conectadas y desconectadas, una biografía familiar, como comentario sobre la experiencia de la migración a través del tiempo. Igualmente, pasó a ser una historia sobre el movimiento y su relación con la violencia, la nostalgia y el deseo, y principalmente, una historia sobre la memoria por medio de los sentidos.

Siena'ga es la creación de nuevas imágenes, en medio de recuerdos, olvidos y fantasías, que permiten no solo un acercamiento no lineal hacia el tiempo, sino también una aproximación a las espirales que lo conforman. Este proyecto no pretende ser un álbum familiar, sino que, a través de estos recorridos por memorias y lugares, quiere interconectar los contextos históricos y cotidianos con las experiencias personales y las relaciones afectivas. Con este enfoque, exploro las sustancias sociales, culturales y personales durante diferentes momentos históricos, como, por ejemplo, el contexto social y político de Ciénaga entre los años treinta y setenta, L'Italia que dejó mi abuelo en los años veinte y, por último, la Italia y la Colombia de hoy en día. Siena'ga se desarrolla a partir de prácticas visuales (fotografía y video) y textuales, en forma de diario, ya que ha sido una forma de sanar y lidiar distancias temporales y espaciales, a la vez que una manera de vivir en medio de esa fragmentación. También es un intento por generar espacios de encuentro y de diálogo que me han permitido acercarme a las historias personales, relaciones afectivas y contextos sociales, políticos, culturales e históricos que me han rodeado.

Por medio de una aproximación textual y visual he ido creando a Siena'ga a través de imágenes $^{3}$ que cargan con sedimentos y residuos del pasado, presente y devenir. De esta manera, Siena'ga 
hace parte de un recorrido por memorias personales y familiares que navega e interconecta tres lugares que han sido, y son, parte de la experiencia histórica de mi familia: Ciénaga y Bogotá (Colombia) y Siena (Italia). Este detour ${ }^{4}$ se da a la vez como documental, ensayo y autobiografía, pero no en el sentido de una narración retrospectiva de mi propia vida, sino en el de una autobiografía, entendida como forma de explorar y aproximarme de las historias inscritas en mi cuerpo, en relación con los otros y con los mundos en los que me ha tocado vivir y me han permeado y cambiado. Así, este proyecto oscila en una línea permeable entre la autobiografía y la etnografía, en ese espacio intimo y vulnerable que se construye por medio de encuentros, intercambios y presencias, en la tensión entre el adentro y el afuera. Como lo expone Deborah Poole (2005), la etnografía está cargada de intimidad y contingencias, y es a través de estas como tenemos que pensar y sentir nuestros trabajos.

El nombre Siena'ga (Siena-Ciénaga) se refiere a ese espacio "entre", al intervalo ${ }^{5}$ en el cual se desarrolla esta autobiografía; es decir, el espacio intermedio "entre" diferentes lugares, memorias, nostalgias y deseos. Esta es una aproximación en la temporalización de los espacios y la especialidad del tiempo. De esta manera, Siena'ga no hace parte de ninguna representación de las "realidades" que me han atravesado, sino, más bien, es un intento de construir una nueva "realidad" a partir de imágenes que dejen entrever las interposiciones temporales y espaciales. Desde esta perspectiva, el presente se rebosa, ya que incluye la actualidad del "tiempo del ahora" y la virtualidad de lo que está por venir (Deleuze, 1989).

como llena de sentido, pero este sentido aparentemente está separado de lo que el mundo puede ser en realidad, o lo que nosotros, con nuestros propios prejuicios podamos insistir en que es su significado" (2009).

4 El detour se refiere a un recorrido sin un rumbo exacto, una aproximación en medio de contingencias, encuentros, conversaciones y lo inesperado.

5 El término intervalo es tomado de Trinh-Minh-ha: "Los intervalos permiten una ruptura y presentan una percepción del espacio en medio de fisuras. Ellos constituyen una serie de interrupciones e irrupciones en la superficie, ellos designan hiatos temporales, distancia, pausa, lapsus y uniones entre diferentes estados". 


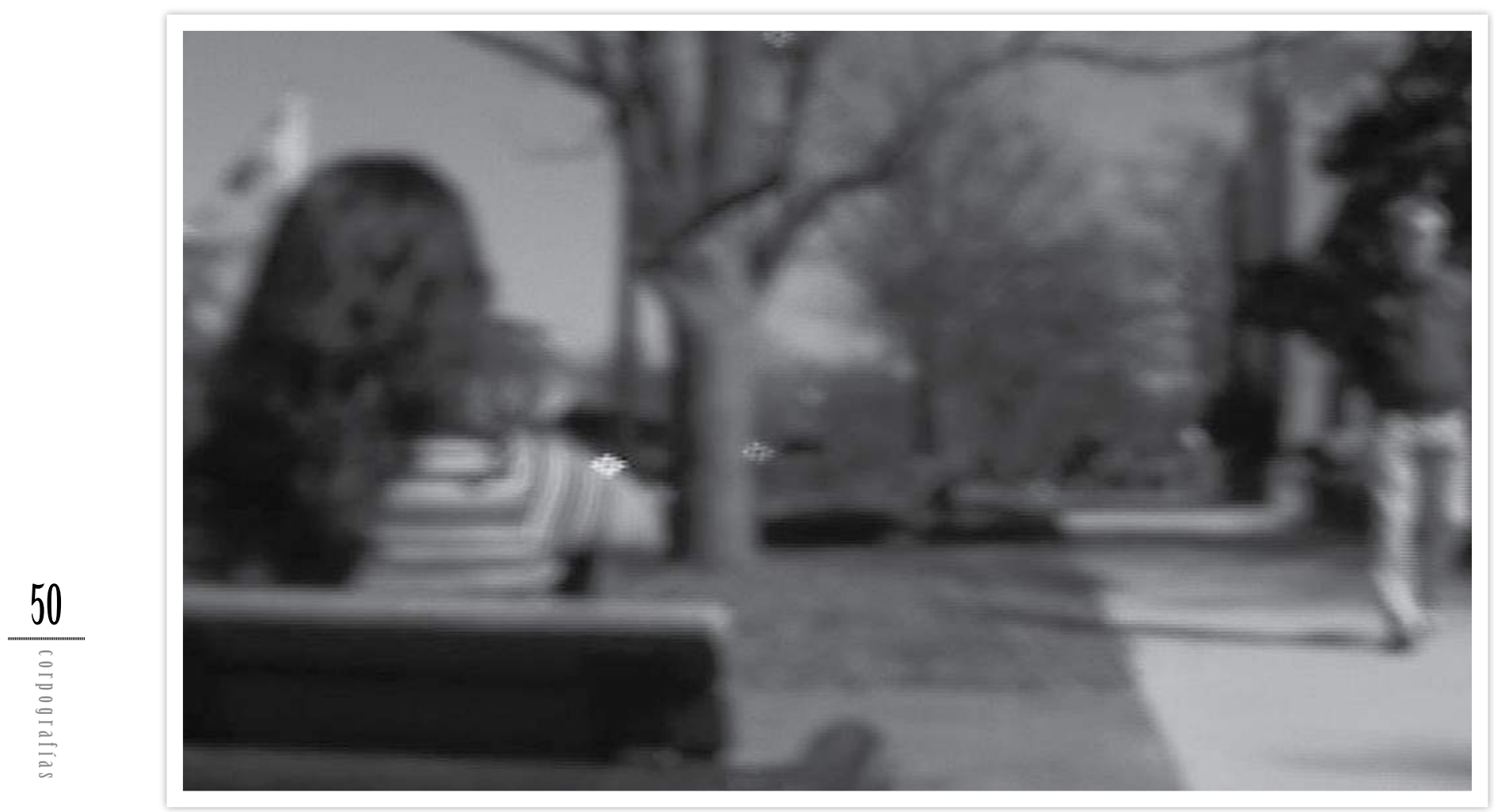

En cada momento la imagen imperfecta de casa...

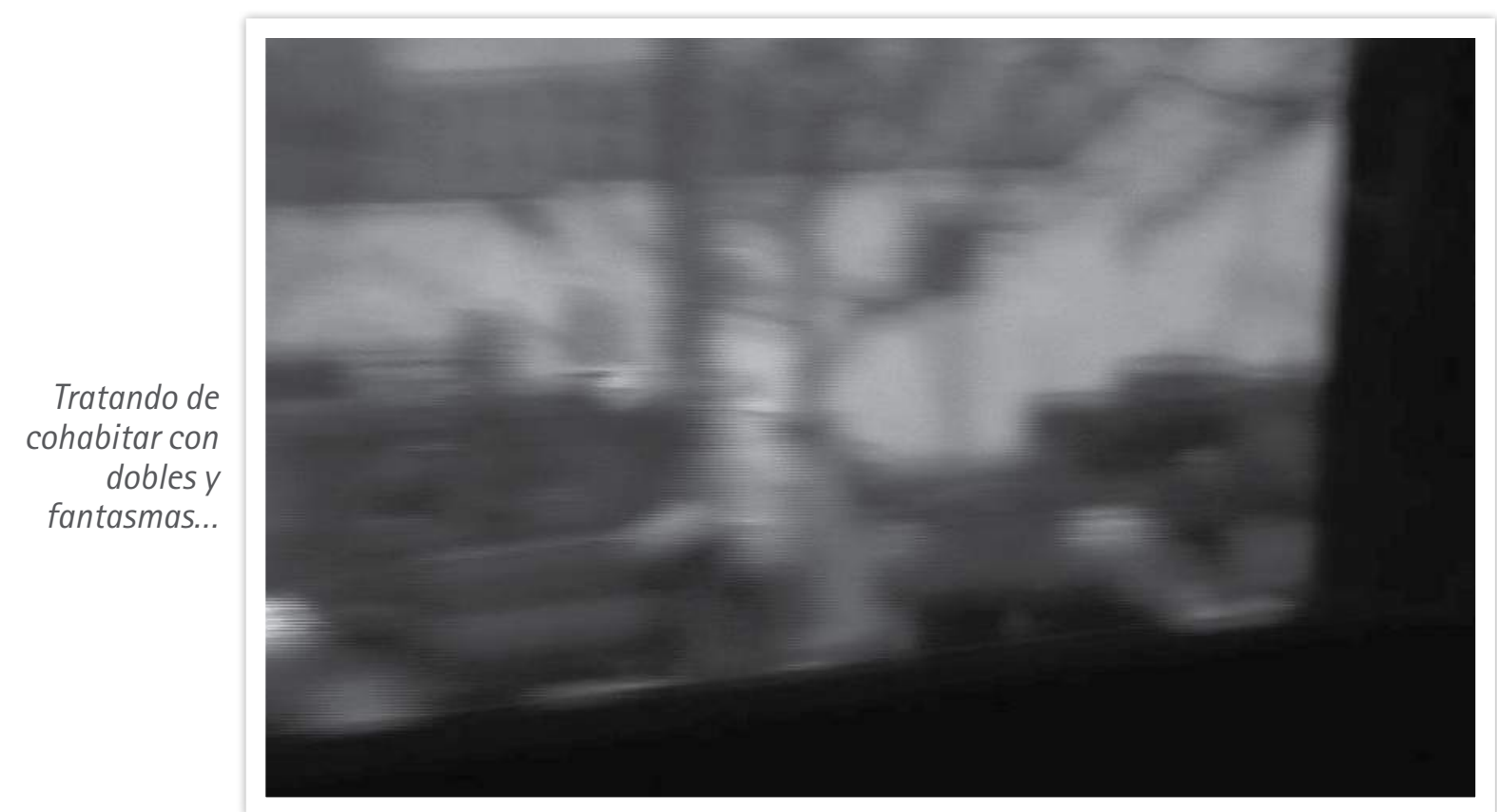




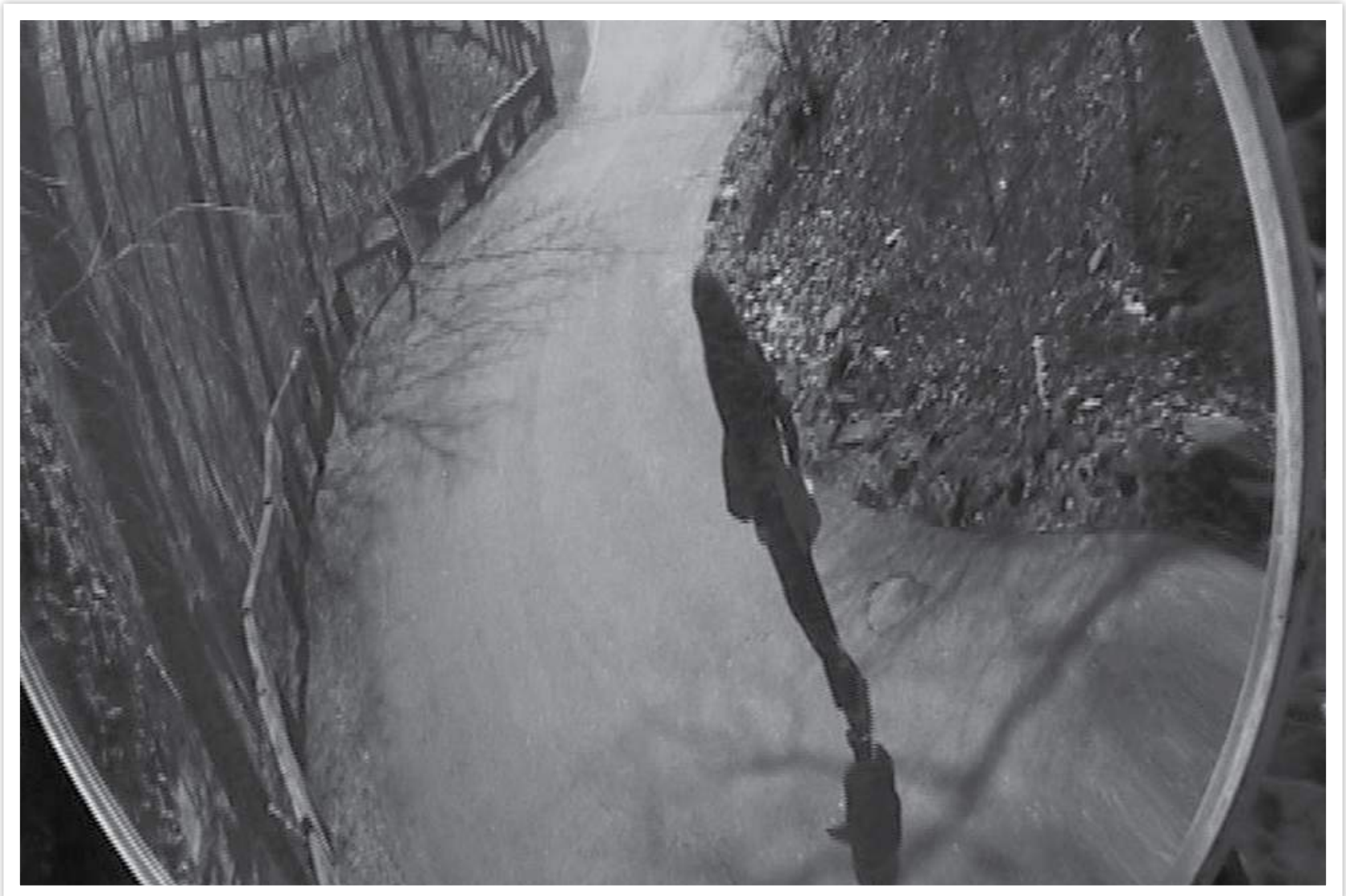

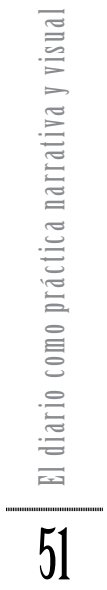

Hay diferentes maneras de estar en los lugares, distintas formas de habitarlos y de entender cómo ellos nos habitan."
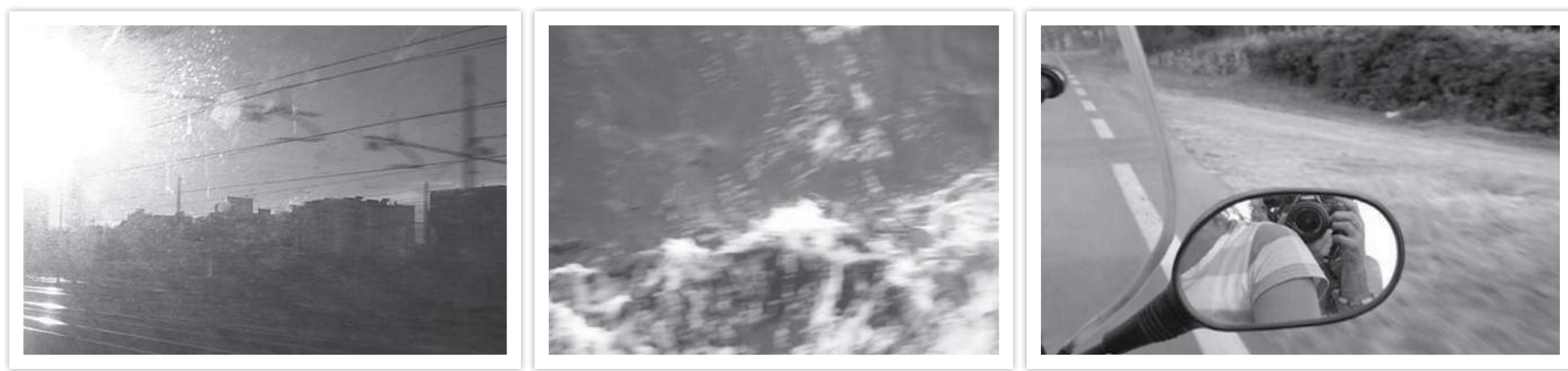

Viviendo en medio de lugares que se interponían con las huellas de otros lugares ya habitados o con deseos de ser habitados. 

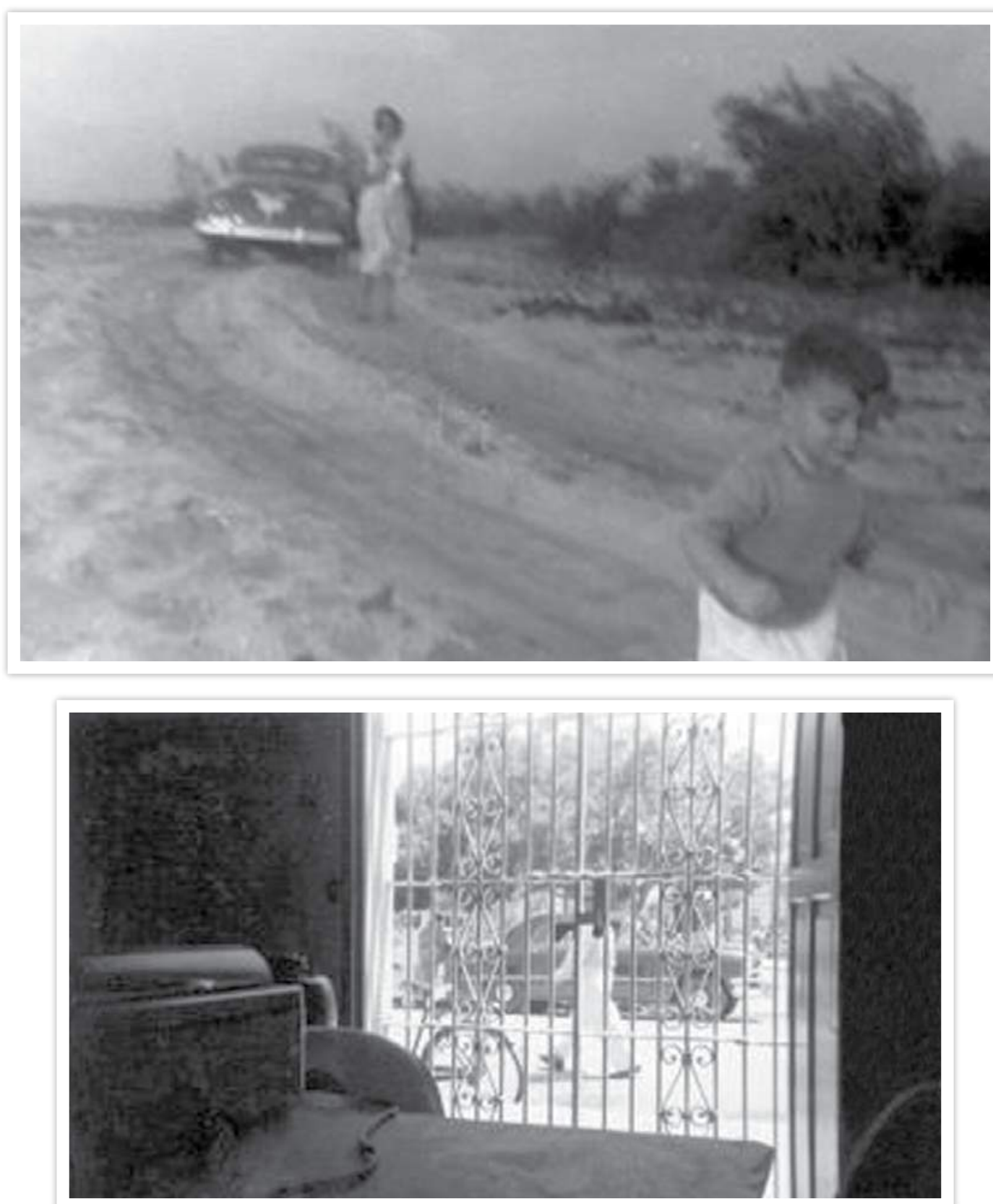

La captura de esos momentos banales nos trae la sustancia misma de ese lugar. La intensidad de haberlo vivido, escuchado o imaginado. 


\section{Fragmentos de Siena'ga \\ RE-MEMBRANZAS ${ }^{6}$}

Este proyecto es el resultado de un proceso de acercamiento audiovisual y etnográfico a diferentes escenarios de memorias de la violencia del Proceso de Comunidades Negras (PCN), la Comunidad de Paz de San José de Apartadó y la Organización de Mujeres Wayuu Munsurat. Mi aproximación a estos escenarios ha sido través de sus formas de rehabitar los espacios y cuerpos tocados por la violencia, de la puesta en escena de los duelos intimos y colectivos, de las prácticas y po-éticas del recordar, al mismo tiempo que de su dimensión política y po-ética, entendiéndolas a la luz de las prácticas cotidianas de resistencia y de resignificación de los espacios de devastación.

Mi intención no fue "documentar" lo sucedido ni reconstruir los hechos ni informar, sino, más bien, realizar una reflexión, a manera de video-ensayo-diario sobre lo que implica acercarse a esos escenarios de memoria, y sobre la misma imposibilidad de "documentar" la memoria. De esta manera, partiendo de la articulación tiempo/ imagen, me interesó reflexionar sobre la misma producción y ensamblaje de imágenes y la posibilidad que estas abren para acercarme a otras temporalidades, a la memoria entendida, en términos de Benjamin, como ruina, que no significa la decadencia, el pasado, sino la interposición y coexistencia de tiempos.

Parto de la imagen dialéctica de la cual habla Benjamin (1997), quien nos plantea la necesidad de aproximarnos y entender la historia a través de las ruinas que nos dejan ver esas violencias inacabadas, entrelazadas con el devenir. Las ruinas, como lo expresa Stoller (2008: 194), tienen que ver principalmente con lo que queda, con las marcas y sedimentaciones que van dejando la diferentes violencias, con el después material y social de estructuras, sensibilidades y cosas. Así, estas imágenes-ruinas, en sentido metafórico y material, están cargadas de tiempo y son una condensación y cristalización del sentido, que conducen hasta su propio límite, donde es preciso escuchar los ruidos, silencios y gritos que lo exceden. Este trabajo es un acercamiento a esos límites y excesos, a la manera como la cotidianidad de las personas que viven en medio de escenarios de terror y en contextos de violencias estructurales, materiales y cotidianas guarda dentro de sí la violencia del acontecimiento y como esta, a su vez, estructura el presente,

6 En línea, en Johannesburg Workshop in Theory and Criticism: http://www.jwtc.org.za/salon_volume_5/catalina_cortes.htm 
silenciosa y fantasmalmente (Das, 2008). Asimismo, a través de la etnografía, la crítica cultural, las prácticas audiovisuales, es una aproximación sensorial a la forma en que se experimenta la violencia en la vida cotidiana, no solo en los espacios de la muerte y la destrucción (Riaño-Alcalá, 2006), sino en los modos en que las víctimas padecen, perciben, persisten y resisten esas violencias; recuerdan sus pérdidas y les hacen duelo, pero también las absorben, las sobrellevan y articulan a su cotidianidad, las usan para su beneficio, las evaden o, simplemente, coexisten con ellas (Das, 2008).

La necesidad que encontré de trabajar a través de lo textual, lo visual y lo sonoro vino de que estos lenguajes permiten un acercamiento más sensorial (Seremetakis, 1996) a las memorias de la violencia y me abren otras formas posibles de aproximación y traducción de los casos expuestos anteriormente. Este video-ensayo-diario pretende mostrar la complejidad de los escenarios de memorias de las violencias $y$, sobre todo, aproximarse a las memorias, hasta encontrarlas en los cuerpos, los sentidos, las sustancias (1996). Es decir, entender las memorias como narraciones testimoniales de corte informativo que no solo se pueden transcribir, archivar y monumentalizar, ya que habitan otros lugares y, consecuentemente, escapan y exceden estas formas. Esta práctica y producción cultural de memoria a través de la aproximación audiovisual a las políticas y po-éticas del recordar que tienen lugar en los escenarios de memoria de la violencia también implica situarse en las políticas y po-éticas audiovisuales propias de los espacios donde se está trabajando, tanto en la forma como en el contenido. Ello requiere ser consciente de cómo las imágenes son responsables de la construcción, representación y percepción de los escenarios de memoria de la violencia. En consecuencia, una de las apuestas es trabajar la relación de la imagen en medio de efectos y afectos, donde la recolección de imágenes y los reensamblajes (Minh-ha, 2005) que componen los escenarios de memorias no pretende simplemente informar, visibilizar y mostrar, sino crear espacios reflexivos y dialógicos a través de formas que afecten y movilicen otras maneras de aproximación, traducción e intervención hacia lo temporal.

Las preguntas que siempre estuvieron presentes durante el proceso de realización de este trabajo, desde la aproximación audiovisual hasta el montaje fueron las siguientes: ¿cómo documentar el repertorio de esos escenarios de memorias?, ¿cómo hacer visibles, a través del trabajo audiovisual y etnográfico, las ausencias y silencios que conforman el presente?, ¿cómo evidenciar y visibilizar las memorias en medio de sus fracturas, borrosidades, discontinuidades y ambigüedades?, ¿qué lenguajes utilizar para traducir esas experiencias de la violencia y trabajar en medio de su irrepresentabilidad? 


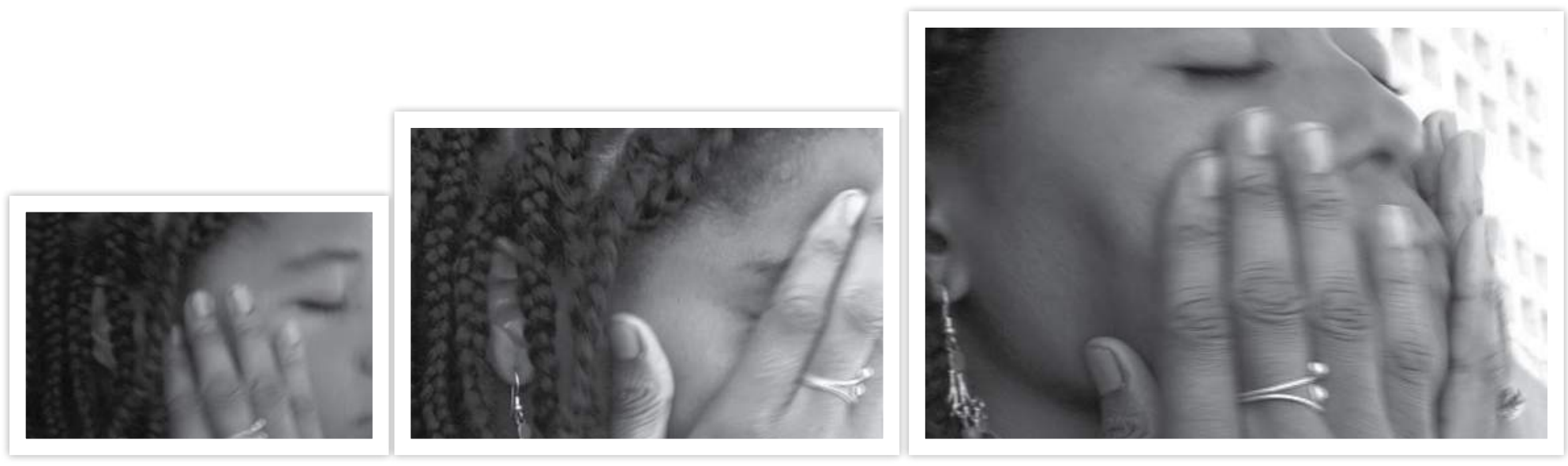

¿Qué queda inscrito en esas miradas que fueron testigo? ¿Cómo contar esas historias inscritas en los cuerpos sin omitir los lenguajes del movimiento, el silencio y la pausa?

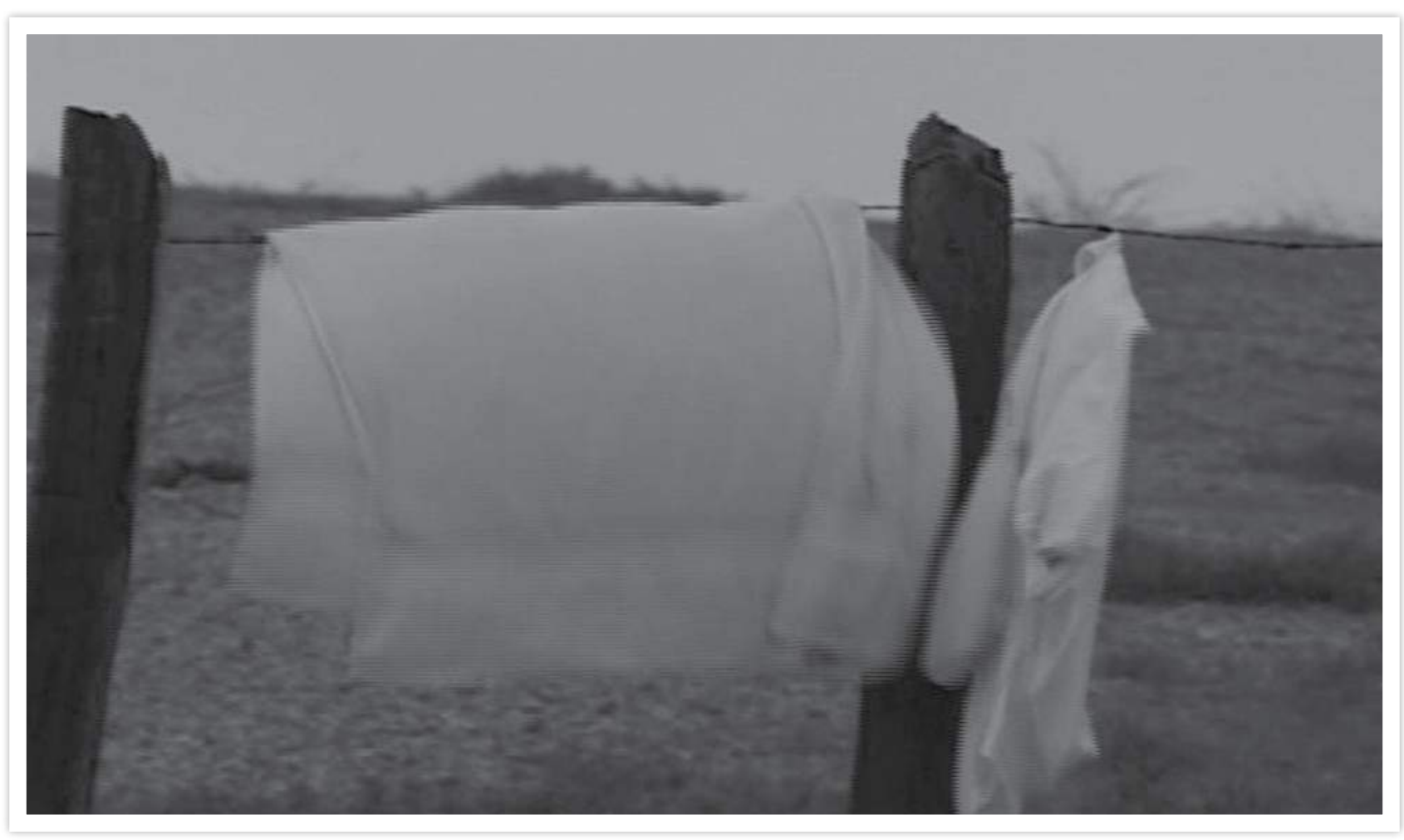




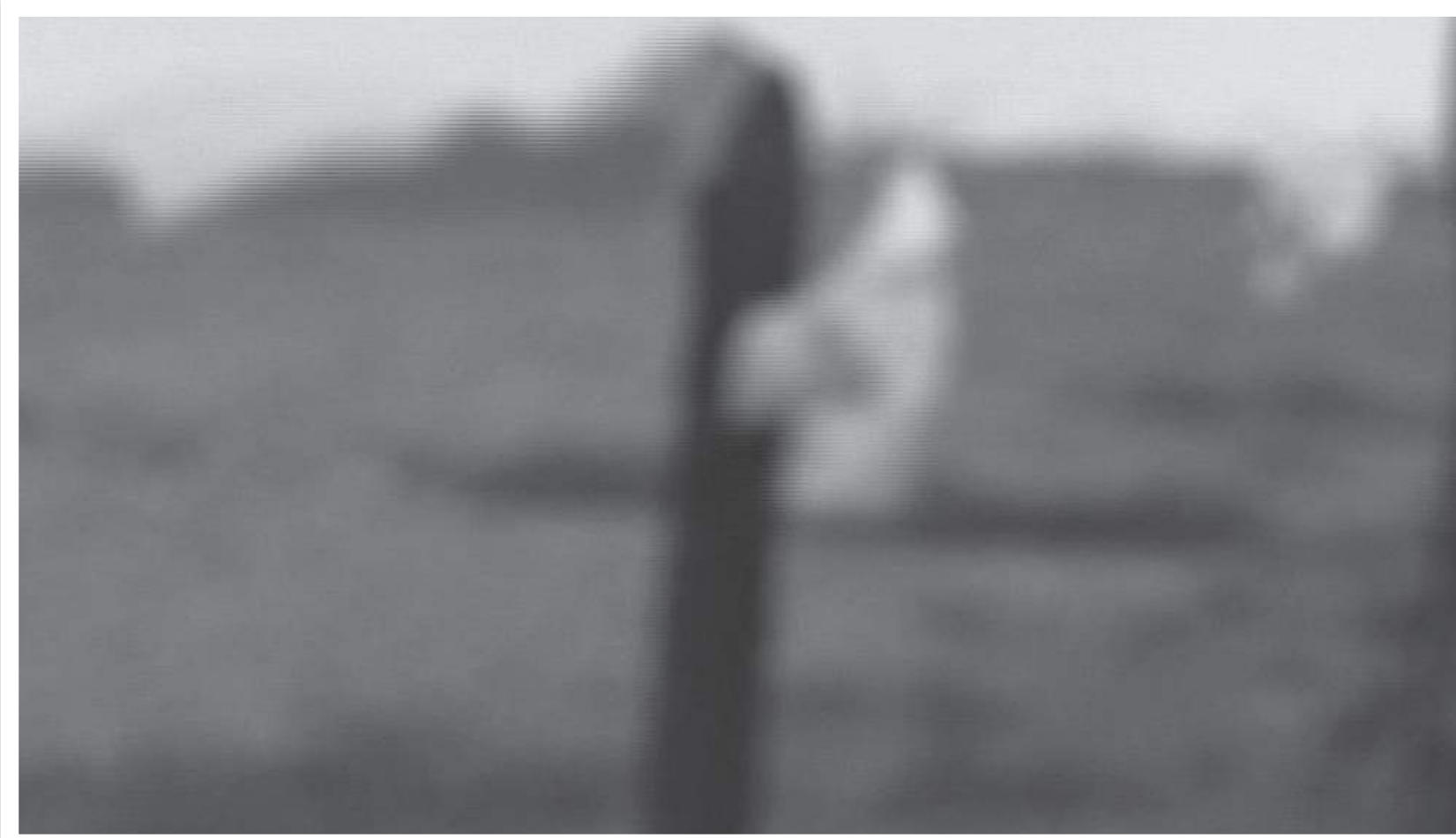

"En medio de lugares devastados, la ropa secándose al viento trae soplos de esperanza. Los deseos e intentos de volver a re-habitar las ruinas. Me detengo y filmo por unos minutos la ropa que mueve el viento y que va cobrando vida poco a poco."
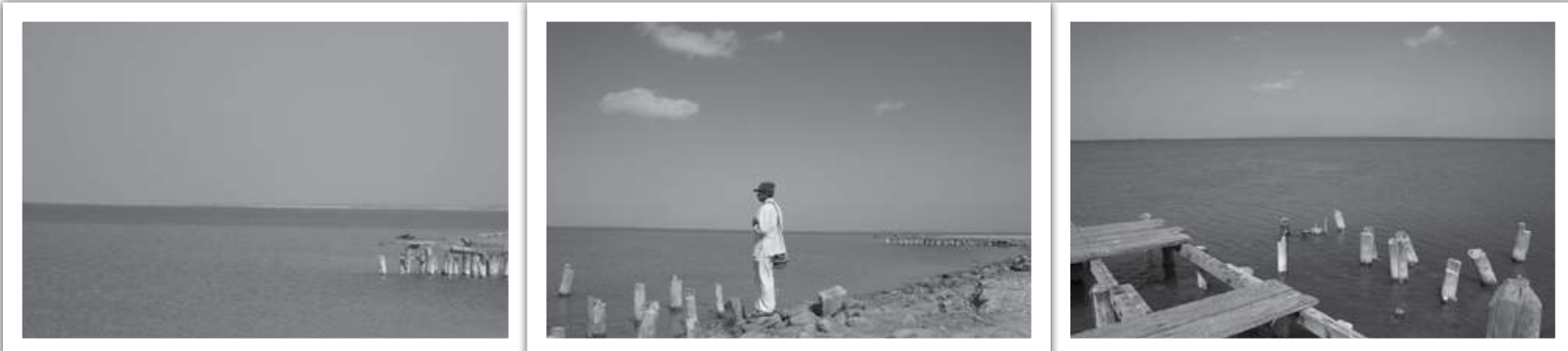

"Hoy en día, de lo que cuentan que fue el puerto de Bahía Portete, un lugar bastante movido donde continuamente entraban y salían embarcaciones, no queda más que un lugar vacio con apenas algunos rastros de vidrios rotos en la orilla y latas. Al llegar ahi con mi cámara trataba de capturar algo que hiciera visible lo que había sido ese puerto, una pista que mostrara las ruinas de un lugar que, por sus condiciones naturales y geográficas, había sido ruta impregnada de historias de violencia, abandono y olvido. Me quedó solo la opción de filmar el vacío que dejaron esos sedimentos de historias. ¿Hacia dónde podría enfocar y dirigir la cámara?" 


\section{Fragmentos de Re-membranzas IMAGEN, COTIDIANIDAD Y DIARIO}

Expuestos los dos proyectos, quiero terminar con una reflexión sobre mi propuesta de entender el diario como práctica narrativa y visual, ya que ello permite trabajar lo visual a partir de los afectos y la cotidianidad, y asi se crea un espacio para plasmar fragmentos de experiencias, reflexiones, meditaciones, impresiones y asociaciones, entre otros. Tanto Siena'ga como Re-membranzas son el producto de la recolección de memorias en diferentes momentos y espacios, a partir de las que se crearon constelaciones que conectaron el presente con posibles futuros, mediante inesperadas yuxtaposiciones (Taussig, 2003). Desde acá, también podemos entender el diario como un espacio de experimentación, donde uno constantemente se mueve entre la distancia y la intimidad, por medio de repeticiones y diferentes ritmos, que van desde lo banal y ordinario de los encuentros, reacciones e impresiones, hasta descripciones densas articuladas con planteamientos teóricos. Así, esta multiplicidad de movimientos entre el adentro y el afuera, lo externo y lo interno, hace parte del trabajo en forma de collage-montaje que nos lleva a explorar diferentes espirales de tiempos y espacios.

El diario, como práctica narrativa y visual, también está relacionado con el caminar como metodología crítica de aproximación, es decir, siguiendo a De Certeau (1984), el caminar como una práctica de lugar a partir de la vida cotidiana que surge en medio de encuentros, recorridos, sonidos, silencios, afectos, deseos, entre otras fuentes cuya sustancia es la cotidianidad. El diario al que me refiero es una mezcla entre el conocido diario de campo de los antropólogos, que hace parte de la práctica etnográfica -y es el espacio donde se permite una gama variada de anotaciones, que incluyen impresiones, sensaciones, la articulación entre los planteamientos teóricos y las descripciones de las experiencias observadas, las conversaciones y los encuentros-, y el sketch visual con el que trabajan muchos artistas, documentalistas, fotógrafos y cineastas para comenzar a explorar sus proyectos visuales. Un ejemplo del sketch-diario visual es el trabajo de Jonas Mekas ${ }^{74}$. Sus diarios filmados dejan ver sus modos de asombrarse, acercarse e indagar en relación con lo que está registrando; la cámara funciona como un lápiz que delinea las sensaciones e impresiones. Enciende la videocámara según la intención del momento, sin un plano preciso, y es en el montaje donde le da cierta sucesión.

Véase el sitio Web oficial de Jonas Mekas: http://www.jonasmekas.com/ 
Hay muchos ejemplos de artistas que utilizan el diario como una forma de narración y de expresión visual; por ejemplo, Sophie Calle, en Historias de pared, toma como punto de partida una experiencia personal de dolor y desolación. Con el fin de decantar esta vivencia y neutralizar su propio sufrimiento, la artista hace de sí misma un receptáculo de narrativas ajenas, en las que la muerte, el abandono y la incomprensión tienen un lugar imperante. Dolor exquisito se despliega en tres partes: la primera consiste en la exhibición de 92 fotografías y algunos objetos efímeros que recuerdan cada uno de los dias del viaje que precedieron a la ruptura, narrada en forma de diario. La segunda parte es una reconstrucción tridimensional de la habitación 261 del hotel Imperial, el sitio de la tragedia amorosa; y en la tercera parte aparecen las narrativas ajenas que dan lugar al exorcismo o la catarsis. Lo que empieza siendo un dolor particular se disemina para dar lugar a una exploración de las condiciones y posibilidades de las emociones humanas. Encontramos aquí un rasgo característico de su trabajo: la labor exhaustiva, cercana a la etnografía, de escuchar relatos ajenos y acercarse a la intimidad de los demás. Es un trabajo que se mueve entre esa línea permeable del adentro y el afuera, la intimidad y la distancia, la imagen y el texto.

Otro trabajo que quiero resaltar aquí es el de Chantal Akerman, cuyos videos se mueven entre la cotidianidad y el diario como forma narrativa y visual, y dejan ver esa mirada inmediata, su interés en las pequeñas acciones que pasan, su relación con la extrañeza de la cotidianidad y los actos que se repiten. En News from home, por medio de la narración en forma de diario y video, nos da la experiencia sensorial del movimiento y la memoria. La línea narrativa del video es la lectura de las cartas que su madre le envía cuando ella se va a vivir a New York. El video deja ver el sentimiento de la alienación urbana y las desconexiones personales y familiares.

Los ejemplos expuestos anteriormente, a partir de su trabajo con la imagen desde el diario, la cotidianidad y la intimidad, están interviniendo en experiencias de sujeción y desubjetivación, al abrir formas de subjetivación y singularización, al igual que dejan ver el papel que puede cumplir la imagen en dichos procesos, los cuales atraviesan la configuración de los tejidos sociales y potencian, a la vez, sus posibles alteraciones en los circuitos afectivos y las distribuciones simbólicas (Quintana, 2012). El diario, como práctica narrativa y visual, abre posibilidades de trabajar con y desde la imagen a través de los afectos, las tensiones y la imaginación. Así, desde este posicionamiento, los procesos de filmar, fotografiar, escribir y editar están permeados por esa materialidad de la mediación y las intensidades que se generan. 


\section{REFERENCIAS}

Benjamin, W. (1997). Sul concetto di Storia. Turin: Einaudi.

_ (1968). Illuminations, essays and reflections. Editado, con Introducción, por H. Arendt. Nueva York: Schocken Books.

Behar, R. (1997). The Vulnerable Observer: Anthropology That Breaks Your Heart. Boston: Beacon.

Buck-Morss, S. (2009). Estudios visuales e imaginación global. Antípoda. Revista de Antropología y Arqueología, 9 (julio-diciembre).

Deleuze, G. (1989). Cinema 2, The Time-Image. Minnesota: University of Minnesota.

Haraway, D. (1991). Simians, Cyborgs and Women: The Reinvention of Nature. Nueva York: Routledge.

Minh-ha, T. (1999). Cinema interval. Nueva York: Routledge.

Minh-ha, Trinh T. (1999). When the moon waxes red. New York and London: Routledge.

Mitchell, W. T. J. (2003). Mostrando el ver: una crítica de la cultura visual. Estudios Visuales, 1, pp. 19-40.

Poole, D. (2005). An Excess of Description: Ethnography, Race and Visual Technologies. Annual Review of Anthropology, 34.

Seremetakis, N., ed. (1996). The Senses Still:Perception and memory as material culture in modernity. Chicago: University of Chicago.

Steward K. (2007). Ordinary Affects. Durham: Duke University.

Taussig, M. (2003). Law in a lawless land. Diary of a Limpieza. Nueva York: New Press.

Quintana, L. (2013). Singularización política o subjetivación ética: dos formas de interrupción frente a la administración de la vida. Revista de Estudios Sociales, 43.

\section{FILMOGRAFíA}

Akerman, Ch., dir. (1977). News from Home. Bélgica:

Mekas, J., dir. (1969). Walden:Diaries, Notes, and Sketches. Paris: Agnes B. DVD\&tR: Voir.

Calle, S., dir. (2012). Historias de pared. Bogotá: Banco de la República.

Marker, Ch., dir. (1983). Sans Soleil. Paris: Argos Films. 